\title{
Article
}

Arq Neuropsiquiatr 2011;69(6):914-919

\section{Neuroimaging in stroke and non-stroke pusher patients}

\author{
Taiza Elaine Grespan Santos-Pontelli, Octavio Marques Pontes-Neto, \\ Draulio Barros de Araujo, Antonio Carlos dos Santos, João Pereira Leite
}

\begin{abstract}
Pusher behavior (PB) is a disorder of postural control affecting patients with encephalic lesions. This study has aimed to identify the brain substrates that are critical for the occurrence of $\mathrm{PB}$, to analyze the influence of the midline shift (MS) and hemorrhagic stroke volume (HSV) on the severity and prognosis of the PB. We identified 31 pusher patients of a neurological unit, mean age $67.4 \pm 11.89,61.3 \%$ male. Additional neurological and functional examinations were assessed. Neuroimaging workup included measurement of the MS, the HSV in patients with hemorrhagic stroke, the analysis of the vascular territory, etiology and side of the lesion. Lesions in the parietal region $(p=0.041)$ and thalamus $(p=0.001)$ were significantly more frequent in PB patients. Neither the MS nor the HSV were correlated with the PB severity or recovery time.
\end{abstract}

Key words: pusher behavior, stroke, postural control.

Análise de neuroimagens de pacientes com síndrome do empurrador decorrente de AVC e outras etiologias

\section{RESUMO}

A síndrome do empurrador (SE) é um distúrbio de controle postural que acomete indivíduos com lesões encefálicas. Os objetivos deste estudo foram identificar as estruturas encefálicas envolvidas na SE, analisar a influência dos desvios de linha média (DLM) e volume do hematoma (VH) na gravidade e duração da SE. Dentre os pacientes internados na enfermaria de neurologia, foram identificados 31 pacientes com SE, idade média $67,4 \pm 11,89,61,3 \%$ homens. Foram realizados exames neurológico e funcional. As análises das neuroimagens incluíram medidas de VH em pacientes com doença cerebrovascular (DC) hemorrágica, DLM, análise do território vascular, etiologia e lado da lesão. Lesão nas regiões parietal $(p=0,041)$ e talâmica $(p=0,001)$ foram significativamente mais frequentes nos pacientes com SE. Não foi observada correlação dos DLM e volume do hematoma com a gravidade e duração da SE.

Palavras-Chave: síndrome do empurrador, doenças cerebrovasculares, controle postural.

The pusher behavior (PB) may be the most intriguing disorder that impairs postural balance after acute encephalic lesions. Patients with PB lean towards the paretic side actively pushing with the nonparetic arm and leg and resist to any attempt of passive correction of their tilted body while sitting or standing ${ }^{1}$.

Traditionally, the occurrence of $\mathrm{PB}$ had been only reported in stroke patients, though this disorder has also been described in non-stroke conditions ${ }^{2}$. Previous imaging studies have suggested the posterolateral thalamus as the typically damaged brain structure in pusher patients $^{3,4}$. Nevertheless, other cortical and subcortical areas such as insular cortex and post-central gyrus ${ }^{5,6}$ have also been pointed out. Therefore, encephalic structures essentially affected in PB patients are still poorly understood.

The aims of this study were to iden- 
tify brain substrates that are critical for the occurrence of $\mathrm{PB}$, to analyze the influence of the midline shift and hemorrhagic stroke volume on the signs and duration of the PB over a 3.5-year period of prospective follow-up.

\section{METHOD}

This was a prospective descriptive observational study that was approved by the ethics committee of our institution. Informed consent was obtained from all subjects or their legal responsible party. Patients with $\mathrm{PB}$ were prospectively identified from inpatients of a neurological emergency unit at a tertiary hospital of the University of São Paulo School of Medicine at Ribeirão Preto. All inpatients were screened by a physical therapist for any abnormal postural behavior by awaking and placing them in a seated position, as soon as clinically possible. If any instability appeared, they were further assessed for PB.

Control group was composed by acute stroke patients with encephalic lesions confirmed by neuroimaging study that did not present $\mathrm{PB}$ and were matched for age and neurologic deficits with the group of patients with PB. Control group presented more previous encephalic lesions than PB group ( $\mathrm{p}=0.027)$. Nevertheless, $95.66 \%$ of the control patients did not present neurologic deficits and were completely independent on their activities of daily living (ADL) before the lesion onset analyzed in this study.

Patients were investigated by a unique qualified examiner (Santos-Pontelli, TEG). PB was assessed using a previously standardized Scale for Contraversive Pushing $(\mathrm{SCP})^{7,8}$. The duration of PB was defined as the interval between injury onset and the complete resolution of $\mathrm{PB}$ signs $(S C P=0)$. Pusher patients were periodically reevaluated (minimum 5; maximum 20 days). The reevaluation intervals were conducted within more than 10 days only after the $90^{\text {th }}$ day post ictus onset.

Severity of neurologic involvement of the patients was assessed by standardized scales such as the National Institutes of Health Stroke Scale (NIHSS) ${ }^{9}$, Glasgow Coma Scale and Revised Trauma Score. Sensory deficits, visual field defects and aphasia were assessed as part of the NIHSS. The degree of paresis of the upper and lower limbs was scored with the usual clinical ordinal scale, where ' 0 ' stands for no trace of movement and ' 5 ' for normal movement. Patients were classified as having spatial neglect when there was clear evidence of a typical clinical behavior such as ' 1 ' a spontaneous deviation of the head and eyes toward the ipsilesional side, '2' orienting toward the ipsilesional side when addressed from the front or the contralesional side, and ' 3 ' ignoring of contralesional located people or objects ${ }^{10}$. If the patient fulfilled these 3 first criteria and was conscious, another four tests were further assessed: "Coping task"; "Clock Drawing test"; "Cancellation test" and "Line bisection test" ${ }^{\prime 0,11}$. Neglect was considered to be present in disoriented patients if they fulfilled the three clinical behaviors and, in conscious and oriented patients, if they fulfilled the criterion for spatial neglect in at least two of the four clinical tests, besides the clinical behavior.

Anosognosia was rated by questioning the patient about limb weakness and confirmed only when no acknowledgement of motor weakness was obtained even after confrontation ${ }^{12}$.

ADL function was assessed by the Barthel Index (BI) which evaluates 10 different abilities and ranges a total score from 0 to 100 points $^{9,13}$.

Uniform rehabilitation was given to all patients while they were hospitalized. Besides motor and respiratory rehabilitation, inpatients treatment included training and orientation of patients' families according to passive or assisted mobilization of the paretic limbs, the correct position while lying and sitting and how to transfer the patients. Moreover, patients were asked to stay in vertical position as long as they could during the day. After discharge, patients were referenced to several public rehabilitation centers, where the rehabilitation treatment was conducted at the discretion of the local resources. The number of physiotherapy sessions per week was obtained from patients' family.

CT or MRI exams were performed as early as possible according to the accessibility of the scanner and the patients' clinical conditions. CT examinations were performed on a Somatom ARC equipment (Siemens, Erlangen, Germany). MRI examinations were performed on a 1.5-T superconductor system (Siemens, Vision Plus, Erlangen Germany). All images were reported and reviewed by one neuroradiologist (Santos, AC) and one neurologist (Pontes-Neto, OM).

The vascular topography, etiology and side of the lesion were determined by combining clinical and neuroimaging data. In order to analyze if there was any correlation between the location of the lesions and the severity of $\mathrm{PB}$ or the recovery time, we considered 1 point to each lesion occurring on thalamus, insula, post-central gyrus and posterior parietal region. These are the brain structures identified in earlier studies to be responsible for the occurrence of $\mathrm{PB}^{3-6}$. Thalamic compression visualized on the neuroimaging scans and confirmed by interthalamic adhesion midline shift was also considered as thalamic lesion.

The midline shift (MS) of the pineal, septum pellucidum and interthalamic adhesion was measured using the E-Film Workstation Medical Imaging Software 1.8.3. The interthalamic adhesion shift was calculated as the distance from the center of the interthalamic adhesion 
to the perpendicular line connecting the anterior and the posterior insertions of the falx cerebri. The pineal and septum pellucidum shifts were similarly measured, as previously described ${ }^{14}$ in the available sequential images.

To measure the hemorrhage volume in patients with hemorrhagic stroke we used the $\mathrm{ABC} / 2$ method $^{15}$ on $\mathrm{CT}$ scans of the acute stroke stage.

Statistical analysis was performed with SPSS (Statistical Package for Social Sciences) Software 13.0 for Windows. Demographic data were summarized by frequency analysis and descriptive statistics, as appropriate. Chisquare test $\left(\mathrm{X}^{2}\right)$ was used to analyze categorical data. Between groups comparisons for continuous data were carried out with Mann-Whiney U test. Spearman correlation coefficient was used to identify correlations between continuous data.
In all tests, the criterion for statistical significance was two-tailed and set at $\alpha<0.05$.

\section{RESULTS}

During the 3.5 years of prospective study we identified 31 patients with PB (25 with stroke, 5 with traumatic brain injury and 1 with brain tumor hemorrhage). Fourteen of them have already been reported ${ }^{2,16,17}$. The control group was matched for age, sex, length of hospital stay, sensory deficits, visual field defects, aphasia, neglect, anosognosia, severe paresis of contralesional upper limb and initial BI. The control group presented less severe paresis of the contralesional limb $(\mathrm{p}=0.022)$ and previous encephalic lesion $(\mathrm{p}=0.027)$ than the $\mathrm{PB}$ group. Nevertheless, $95.66 \%$ of control patients did not present neurologic deficits and were completely inde-

Table 1. Demographic and clinical data of patients with and without pusher behavior.

\begin{tabular}{|c|c|c|c|c|}
\hline Data & Nonpushers & Pushers & Pushers with stroke & Pushers with TBI \\
\hline Frequency & 23 & $31^{*}$ & 25 & 5 \\
\hline Stroke / TBI & 23 & $25 / 5$ & - & - \\
\hline IS / HS & $19 / 4$ & $13 / 10^{* *}$ & $13 / 10^{* *}$ & - \\
\hline Age (mean $\pm S D)$ & $65.26 \pm 12.96$ & $67.4 \pm 11.89$ & $68.84 \pm 10.9$ & $62.2 \pm 16.52$ \\
\hline Male \% & 52.2 & 61.3 & 60 & 80 \\
\hline Right brain lesion \% & 56.5 & 61.3 & 56 & 80 \\
\hline Previous brain lesion \% & 43.5 & 16.1 & 16 & 20 \\
\hline $\begin{array}{l}\text { First evaluation } \\
\text { Time post ictus onset (median / min-max) }\end{array}$ & $7 / 1-25$ & $10.5 / 1-60$ & $9.5 / 1-60$ & $13.60 / 8-27$ \\
\hline \multicolumn{5}{|l|}{ Time in Hospital } \\
\hline$($ mean $\pm S D)$ & $22.65 \pm 17.0$ & $26.07 \pm 20.2$ & $26.07 \pm 18.5$ & $24.2 \pm 14.49$ \\
\hline NIHSS (mean $\pm S D$ ) & $13.91 \pm 4.68$ & $18.24 \pm 4.9$ & $18.24 \pm 4.9$ & $13.75 \pm 7.23$ \\
\hline RTS (mean $\pm S D)$ & - & $6.66 \pm 0.86$ & - & $6.66 \pm 0.86$ \\
\hline \multicolumn{5}{|l|}{ Severe paresis } \\
\hline Superior limb \% & 56.5 & 77.4 & 84 & 40 \\
\hline Inferior limb \% & 43.5 & 74.2 & 80 & 40 \\
\hline Neglect \% & 23.1 & 35.5 & 32 & 40 \\
\hline Anosognosia \% & 0 & 6.5 & 8 & 0 \\
\hline Number assessed & 18 & 18 & 15 & 3 \\
\hline Sensitive deficit \% & 60.9 & 61.3 & 68 & 20 \\
\hline Hemoanopia \% & 47.8 & 64.5 & 72 & 20 \\
\hline Aphasia \% & 52.2 & 61.2 & 68 & 40 \\
\hline $\begin{array}{l}\text { Physiotherapy after discharge } \\
\text { sessions / week (mean } \pm \text { SD) }\end{array}$ & $1.10 \pm 1.07$ & $1.32 \pm 1.35$ & $1.3 \pm 1.25$ & $1.33 \pm 2.3$ \\
\hline SCP $1^{\text {st }}$ evaluation (mean $\pm S D$ ) & 0 & $5.81 \pm 0.4$ & $5.98 \pm 0.69$ & $5.3 \pm 0.83$ \\
\hline $\mathrm{Bl} 1^{\text {st }}$ evaluation (number assessed) (mean $\pm S D$ ) & $23(2.83 \pm 6.54)$ & $31(1.77 \pm 4.75)$ & $25(1.4 \pm 3.36)$ & $5(4 \pm 8.94)$ \\
\hline $\mathrm{BI}$ without PB (number assessed) (mean $\pm \mathrm{SD}$ ) & - & $18(40.56 \pm 25.3)$ & $14(40.36 \pm 23.4)$ & $4(41.25 \pm 35.7)$ \\
\hline $\begin{array}{l}\text { PB recovery time (number assessed) } \\
\text { (median / min-max) }\end{array}$ & - & $22(53.5$ / 8-789) & $18(61.5$ / 19-789) & $4(26$ / 8-30) \\
\hline
\end{tabular}

PB: pusher behavior; NIHSS: National Institute of Health Stroke Scale; RTS: Revised Trauma Scale; BI: Barthel Index; TBI: Traumatic Brain Injury; IS: Ischemic Stroke; HS: Hemorrhagic Stroke; SCP: Scale for Contraversive Pushing. *Includes 1 patient with brain tumor hemorrhage; ${ }^{*} 2$ patients presented hemorrhagic transformation following ischemic stroke; ${ }^{* *} 1$ patient still presented PB and 3 died. 
Table 2. Relative frequency of encephalic lesions in pusher and control patients.

\begin{tabular}{|c|c|c|c|}
\hline Lesions & Pusher patients (\%) & Control patients (\%) & Statistic test / p \\
\hline Thalamus & 80.6 & 40.9 & Qui-square / 0.001 \\
\hline Lesion & 41.9 & 18.2 & \\
\hline Compression & 38.7 & 22.7 & \\
\hline Insula & 58.1 & 54.5 & Qui-square / 0.799 \\
\hline Post-central gyrus & 58.1 & 36.4 & Qui-square / 0.119 \\
\hline Posterior parietal region & 45.2 & 18.2 & Qui-square / 0.041 \\
\hline
\end{tabular}

pendent on their activities of daily living before the lesion onset analyzed in this study. Table 1 describes the demographic and clinical characteristics of the patients.

All patients, except for one, took less than 24 hours from stroke onset to the first CT scan acquisition. This PB patient was excluded only from the analysis of MS and hemorrhagic stroke volume. MRI scan acquisition was taken in $12 \mathrm{~PB}$ and 5 control patients within a median time of 35 days.

The middle cerebral artery (MCA) territory was predominantly injured in ischemic stroke patients with and without PB. A wide range in topography and lesion size was observed in both control and PB patients. Neuroimaging scans showed a range from no visible lesions to hemispheric lesions affecting more than one related encephalic structure in both groups.

The number of $\mathrm{PB}$ related structure lesions was greater in the PB group $(\mathrm{p}=0.013)$ but there was no correlation between the frequency of the lesions with either the severity or with the prognosis of the PB (Table 2).

Among all control and PB patients with ischemic stroke, there was a positive correlation between MS and NIHSS score (septum pellucidum: $\mathrm{p}=0.020 / \mathrm{r}=0.402$; interthalamic adhesion: $\mathrm{p}=0.021 / \mathrm{r}=0.40$; pineal: $\mathrm{p}=0.023$ / $r=0.394)$. Nevertheless, there was no correlation between these variables among PB patients only. There was a positive correlation between NIHSS score and HSV in hemorrhagic stroke PB patients $(\mathrm{p}=0.039 / \mathrm{r}=0.732)$. There were no significant correlations of MS and HSV with severity or prognosis of $\mathrm{PB}$.

\section{DISCUSSION}

Studies comparing neuroimaging data and neurologic deficits in patients with PB have already been conducted. However, this is the first attempt to analyze the relationship between neuroimaging data and the severity and prognosis of PB. Additionally, in the present study, for the first time, a neuroimaging analysis included stroke and non-stroke PB patients.

A positive correlation of the NIHSS score with HSV in hemorrhagic stroke PB patients was found. In spite of this fact, neither the NIHSS score nor HSV were related with the severity or recovery time of PB. Conversely, previous studies showed that the hemorrhagic volume is highly associated with functional and neurologic deficits $^{18}$. These data and the fact that the NIHSS score is a good neurologic outcome predictor ${ }^{19-21}$ indicate that the PB evolution and severity may be independent from other neurologic deficits such as those measured by the NIHSS. However, more research is needed to confirm this observation.

No correlation was found between NIHSS score and MS in PB patients, and neither the NIHSS score nor MS were related with the severity or recovery time of PB. In fact, according to Lam et al., MS is not sensitive enough to predict patient's final outcome of general neurological deficits ${ }^{22}$.

The qualitative analysis of each neuroimaging scan revealed many similarities between the $\mathrm{PB}$ and control patients. We found lesions on the anterior and posterior crus of the internal capsule, thalamus, frontal, temporal and parietal lobes, insula and also hemispheric lesions in both PB and control patient's neuroimaging scans. Apparently, similar lesions can result in completely distinct reactions.

It is known that slight differences in thalamic lesion locations can cause completely distinct syndromes ${ }^{4,6,23}$. This includes, among postural control dysfunctions, vestibular syndromes with disturbances of visual verticality perception and skew deviation ${ }^{23,24}$, thalamic astasia ${ }^{25}$ and $\mathrm{PB}{ }^{4,6}$ The latter has already been associated with the interoceptive system dysfunction ${ }^{26}$ but, until now, the neural network of this system is not well known. Nevertheless, it would be possible that distinct neurologic and postural deficits could depend on the location of this network's lesion.

Recently, Ticini et al., found that the posterior thalamus itself rather than additional malperfusion in distant cortical areas is integral to the occurrence of $\mathrm{PB}^{6}$. Moreover, they found no damage or malperfusion on the thalamus of patients with PB caused by extra-thalamic lesions. These findings indicate that the isolated thalamic as well as the isolated extra-thalamic brain structures 
previously related to the $\mathrm{PB}$ contribute to the network controlling upright body ${ }^{6}$.

Johansen et al. analyzed neuroimaging scans of PB patients with a well matched control group ${ }^{5,27}$. However, these areas were identified with the subtraction technique where the percentage of difference between the $\mathrm{PB}$ and control patients neuroimaging scans was not exclusively 100\% (ranged from 81 to 100\%). Although being a meticulous study, this analysis does not exclude the same PB patients' lesion location existence in control patients. Therefore, the fact that patients with and without PB have apparent similar encephalic lesions is not completely elucidated.

Although the MCA territory was the most common vascular territory affected by ischemic stroke in PB patients, no obvious pattern was observed. There was a substantial heterogeneity of the lesion size and topography both in the PB and control patients. The present results corroborate with the observations of Pérennou et al. ${ }^{28}$, Premoselli et al. ${ }^{29}$ and Pedersen et al. ${ }^{30}$. The last authors compared the frequency of lesion locations in pusher and control patients and found a significant difference in the posterior crus of the internal capsule. Conversely, Reding et al. ${ }^{27}$ described other encephalic structures that seemed to be involved with PB as Paci et al. ${ }^{31}$ found the $\mathrm{PB}$ in a patient with cerebelar ischemic stroke and Karnath et al..$^{32}$ recently reported a patient with PB due to a right-hemisphere ischeamia clearly affecting the anterior cerebral artery territory. Overlap neuroimaging workups have indicated the posterolateral thalamus, insula and post-central gyrus as the critical structures for PB occurrence ${ }^{4-6}$.

We conducted an additional analysis of the lesion on the thalamus, insula, post-central gyrus and posterior parietal region. Although the posterior parietal region was not previously confirmed as a PB related topography, it was included since this area is part of the sensory-motor network that process multisensory inputs used in motor responses, especially those directed to the extrapersonal space $^{10,33}$. Therefore, this area could be related to the PB patients' motor reaction caused by the severe conflict between the perception of body and visual verticality. In fact, we observed that the lesion of this area and the thalamus was significantly more frequent in $\mathrm{PB}$ than in control patients. Almost half PB patients presented lesions on the posterior parietal region and it is consistent in the literature that neglect and aphasia is especially frequent in patients with $\mathrm{PB}{ }^{1,5,27,30}$. Furthermore, since the neural network that processes the postural perception has several participating areas and there was no absolute method that could isolate a strict PB lesion, it is possible that the posterior parietal region was, until now, not recognized. PB does not occur essentially due to neglect or aphasia, but the posterior parietal region can probably participate in the processing of the graviceptive information about upright body orientation. However, these data certainly cannot prove the association between the posterior parietal region and the PB. Further research using lesion overlap and subtraction techniques is needed to confirm the critical structures for the occurrence of PB, including stroke and non-stroke conditions.

\section{REFERENCES}

1. Davies PM. Steps to follow: a guide to the treatment of adult hemiplegia. New York: Springer, 1985:279-305.

2. Santos-Pontelli TE, Pontes-Neto OM, Colafemina JF, de Araujo DB, Santos AC, Leite JP. Contraversive pushing in non-stroke patients. J Neurol 2004; 251:1324-1328.

3. Karnath $\mathrm{HO}$, Ferber S, Dichgans J. The neural representation of postural control in humans. Proc Natl Acad Sci U S A 2000;97:13931-13936.

4. Karnath HO, Johannsen L, Broetz D, Kuker W. Posterior thalamic hemorrhage induces "pusher syndrome". Neurology 2005;64:1014-1019.

5. Johannsen L, Broetz D, Naegele T, Karnath HO. "Pusher syndrome" following cortical lesions that spare the thalamus. J Neurol 2006;253: 455-463.

6. Ticini LF, Klose U, Nagele T, Karnath HO. Perfusion imaging in Pusher syndrome to investigate the neural substrates involved in controlling upright body position. PLoS One 2009;4:e5737.

7. Karnath $\mathrm{HO}$, Brotz D, Gotz A. Clinical symptoms, origin, and therapy of the "pusher syndrome". Nervenarzt 2001;72:86-92.

8. Karnath HO, Brotz D. Instructions for the Clinical Scale for Contraversive Pushing (SCP). Neurorehabil Neural Repair 2007;21:370-371.

9. Cincura C, Pontes-Neto OM, Neville IS, et al. Validation of the National Institutes of Health Stroke Scale, modified Rankin Scale and Barthel Index in Brazil: the role of cultural adaptation and structured interviewing. Cerebrovasc Dis 2009;27:119-122.

10. Kerkhoff G. Spatial hemineglect in humans. Prog Neurobiol 2001;63:1-27.

11. Plummer P, Morris ME, Dunai J. Assessment of unilateral neglect. Phys Ther 2003;83:732-740.

12. Bisiach E, Vallar G, Perani D, Papagno C, Berti A. Unawareness of disease following lesions of the right hemisphere: anosognosia for hemiplegia and anosognosia for hemianopia. Neuropsychologia 1986;24:471-482.

13. Mahoney Fl, Barthel DW. Functional evaluation: the barthel index. Md State Med J 1965;14:61-65.

14. Zazulia AR, Diringer MN, Derdeyn CP, Powers WJ. Progression of mass effect after intracerebral hemorrhage. Stroke 1999;30:1167-1173.

15. Kothari RU, Brott T, Broderick JP, et al. The ABCs of measuring intracerebral hemorrhage volumes. Stroke 1996;27:1304-1305.

16. Santos-Pontelli TE, Pontes-Neto OM, Colafemina JF, Araujo DB, Santos AC, Leite JP. Pushing behavior and hemiparesis: which is critical for functional recovery in pusher patients? Case report. Arq Neuropsiquiatr 2007;65: 536-539.

17. Pontelli TE, Pontes-Neto OM, Colafemina JF, Araujo DB, Santos AC, Leite $J P$. Posture control in pusher syndrome: influence of lateral semicircular canals. Rev Bras Otorrinolaringol (Engl Ed) 2005;71:448-452.

18. Priorities for clinical research in intracerebral hemorrhage: report from a National Institute of Neurological Disorders and Stroke workshop. Stroke 2005;36:e23-41.

19. Wilde EA, McCauley SR, Kelly TM, et al. Feasibility of the Neurological Outcome Scale for Traumatic Brain Injury (NOS-TBI) in adults. J Neurotrauma 2010;27:975-981.

20. Wilde EA, McCauley SR, Kelly TM, et al. The Neurological Outcome Scale for Traumatic Brain Injury (NOS-TBI): I. Construct validity. J Neurotrauma 2010;27:983-989.

21. Wityk RJ, Pessin MS, Kaplan RF, Caplan LR. Serial assessment of acute stroke using the NIH Stroke Scale. Stroke 1994;25:362-365.

22. Lam WW, Leung TW, Chu WC, Yeung DT, Wong LK, Poon WS. Early computed tomography features in extensive middle cerebral artery territory infarct: prediction of survival. J Neurol Neurosurg Psychiatry 2005;76:354-357.

23. Dieterich M, Brandt T. Thalamic infarctions: differential effects on vestibular function in the roll plane (35 patients). Neurology 1993;43:1732-1740. 
24. Dieterich M, Bartenstein P, Spiegel S, Bense S, Schwaiger M, Brandt T. Thalamic infarctions cause side-specific suppression of vestibular cortex activations. Brain 2005;128:2052-2067.

25. Masdeu JC, Gorelick PB. Thalamic astasia: inability to stand after unilateral thalamic lesions. Ann Neurol 1988;23:596-603.

26. Karnath $\mathrm{HO}$, Ferber S, Dichgans J. The origin of contraversive pushing: evidence for a second graviceptive system in humans. Neurology 2000;55: 1298-1304.

27. Reding M, David A, Volpe B. Neuroimaging study of the pusher syndrome post stroke. XVI World Congress of Neurology, Buenos Aires, Argentina, September 14-19. J Neurol Sci 1997;150(Suppl):S129.

28. Perennou DA, Amblard B, Leblond C, Pelissier J. Biased postural vertical in humans with hemispheric cerebral lesions. Neurosci Lett 1998;252: 75-78.
29. Premoselli S, Cesana L, Cerri C. Pusher syndrome in stroke: clinical, neuropsychological, and neurophysiological investigation. Eur Med Phys 2001 37:143-151.

30. Pedersen PM, Wandel A, Jorgensen HS, Nakayama H, Raaschou HO, Olsen TS. Ipsilateral pushing in stroke: incidence, relation to neuropsychological symptoms, and impact on rehabilitation. The Copenhagen Stroke Study. Arch Phys Med Rehabil 1996;77:25-28.

31. Paci $M$, Nannetti L. The pusher syndrome in a patient with cerebellar infarction. Physiother Res Int 2005;10:176-177.

32. Karnath $\mathrm{HO}$, Suchan J, Johannsen L. Pusher syndrome after ACA territory infarction. Eur J Neurol 2008;15:e84-e85.

33. Lafosse $\mathrm{C}$, Kerckhofs $\mathrm{E}$, Troch $\mathrm{M}$, et al. Contraversive pushing and inattention of the contralesional hemispace. J Clin Exp Neuropsychol 2005; 27:460-484. 